\title{
The prevalence of Human polyomavirus 2 (HPyV2) antibody positivity in psoriasis patients
}

Molloy, O. E.

2020-06

Molloy, O E , Malara , A , Hassan , J , Lynch , M , Clowry , J , Hedman , K, De Gascun , C F \& Kirby , B 2020 , ' The prevalence of Human polyomavirus 2 (HPyV2) antibody positivity in psoriasis patients ' , Journal of Clinical Virology , vol. 127 , 104368 . https://doi.org/10.1016/j.jcv.2020.104368

http://hdl.handle.net/10138/329508

https://doi.org/10.1016/j.jcv.2020.104368

cc_by_nc_nd

acceptedVersion

Downloaded from Helda, University of Helsinki institutional repository.

This is an electronic reprint of the original article.

This reprint may differ from the original in pagination and typographic detail.

Please cite the original version. 


\section{Journal Pre-proof}

The prevalence of Human polyomavirus 2 (HPyV2) antibody positivity in psoriasis patients

OE Molloy (Conceptualization) (Methodology) (Data curation) (Visualization) (Writing - original draft) (Writing - review and editing),

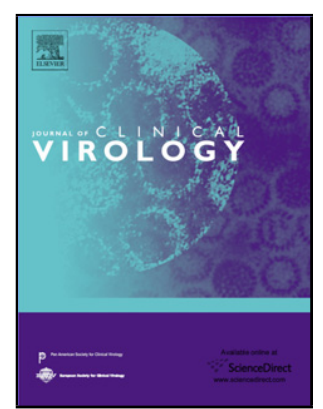
A Malara (Data curation), J Hassan (Investigation) (Writing - review and editing), M Lynch (Data curation), J Clowry (Data curation), K Hedman (Investigation), CF De Gascun (Conceptualization) (Resources) (Investigation) (Writing - review and editing), B Kirby (Conceptualization) (Methodology) (Writing - review and editing) (Supervision)

PII:

DOI:

Reference:

To appear in:

Received Date:

Revised Date:

Accepted Date:

\author{
S1386-6532(20)30110-4 \\ https://doi.org/10.1016/j.jcv.2020.104368 \\ JCV 104368
}

Journal of Clinical Virology

15 January 2020

7 April 2020

9 April 2020

Please cite this article as: Molloy O, Malara A, Hassan J, Lynch M, Clowry J, Hedman K, De Gascun C, Kirby B, The prevalence of Human polyomavirus 2 (HPyV2) antibody positivity in psoriasis patients, Journal of Clinical Virology (2020), doi: https://doi.org/10.1016/j.jcv.2020.104368 
This is a PDF file of an article that has undergone enhancements after acceptance, such as the addition of a cover page and metadata, and formatting for readability, but it is not yet the definitive version of record. This version will undergo additional copyediting, typesetting and review before it is published in its final form, but we are providing this version to give early visibility of the article. Please note that, during the production process, errors may be discovered which could affect the content, and all legal disclaimers that apply to the journal pertain.

(C) 2020 Published by Elsevier. 
Title page

The prevalence of Human polyomavirus 2 (HPyV2) antibody positivity in psoriasis patients.

OE Molloy ${ }^{\mathrm{a}}$, A Malaraa, J Hassan ${ }^{\mathrm{b}}$, M Lynch ${ }^{\mathrm{a}}$, J Clowry ${ }^{\mathrm{a}}$, K Hedman ${ }^{\mathrm{d}}$, CF De Gascun ${ }^{\mathrm{b}}$, B Kirby. ${ }^{\mathrm{a}, \mathrm{c}}$

aThe Charles Centre for Dermatology. St. Vincent's University Hospital, Dublin, Ireland.

${ }^{\text {b}}$ The National Virus Reference Laboratory. University College Dublin, Ireland.

'The Charles Institute for Dermatology, School of Medicine, University College Dublin.

${ }^{\mathrm{d}}$ The Department of Virology, University of Helsinki, and Helsinki University Hospital, Helsinki, Finland.

Word count : 2236, including abstract.

*Correspondence to:

Dr. Oonagh Molloy.

Specialist Research Registrar in Dermatology., St. Vincent's University Hospital, Elm Park, Dublin 4.

oonaghmolloy@svhg.ie

molloyoona@yahoo.co.uk Telephone: 0035312214189

Co authors:

Anna Malara, PhD. Post Doc Immunology, Business Development Manager, UCD Clinical Research Centre.

anna.malara@ucd.ie

Jaythoon Hassan PhD, FACSLM, FRCPath (Immunology)

Senior Clinical Scientist \& Principal Investigator, National Virus Reference Laboratory, University College Dublin, Belfield, Dublin 4.

Email: jaythoon.hassan@ucd.ie 
Dr. Maeve Lynch

Department of Dermatology, St. Vincent's University Hospital, Elm Park Dublin 4.

Email: lynchmaeve@yahoo.ie

Dr. Julianne Clowry

Department of Dermatology, St.Vincent's University Hospital, Elm Park, Dublin 4.

Email: julianneclowry@hotmail.ie

Dr. Cillian De Gascun

MD, FRCPI, FRCPath (Virology), FFPathRCPI

Consultant Virologist \& Laboratory Director

UCD National Virus Reference Laboratory, Belfield Campus, Dublin 4

Email: cillian.degascun@ucd.ie

Klaus Hedman, MD, PhD. Professor in Clinical Virology,

Dept. Virology, University of Helsinki;, Chief Physician at HUSLAB, Haartmaninkatu 3., FI00290 Helsinki, Finland.

E-mail: klaus.hedman@helsinki.fi

Professor Brian Kirby

Full Professor of Dermatology

The Charles Centre for Dermatology. St. Vincent's University Hospital, Dublin, Ireland.

The Charles Institute for Dermatology, School of Medicine, University College Dublin.

Email: bkirby@svhg.ie

\section{Highlights}


- Infection with human polyomavirus 2 (HPyV2) is common.

- Reactivation of HPyV2 in immunocompromised hosts may rarely lead to a serious illness- progressive multifocal leucoencephalopathy (PML).

- HPyV2 induced PML has been reported in association with systemic and biologic treatments for psoriasis, rheumatoid arthritis, haematological malignancy and multiple sclerosis.

- The prevalence of HPyV2 has not been measured in a psoriasis cohort to date.

\section{Background}

HPyV2 is a double stranded, deoxyribonucleic acid (dsDNA) human polyomavirus discovered in the 1960s on electron microscopy by Zu Rhein and Chou and cultured in 1971 by Walker et al. [2]. Antibodies to HPyV2 are present in $30-70 \%$ of the background population with some reports suggesting an asymptomatic carriage rate of up to $90 \%$ [3]. The primary route of transmission for HPyV2 is ingestion, with the tonsils the primary site of viral replication. After resolution of the viremia associated with the primary infection, HPyV2 remains latent in the renal tract. The virus can reactivate in immunosuppressed states. This reactivation can lead rarely to a rapidly progressive neurological condition; progressive multifocal leukoencephalopathy- PML [4]. The background incidence of PML is thought to be < $0.3 / 100,000$ person years $[5,6]$. Prior to the advent of combined anti-retroviral therapy 
(ART) for treating human immunodeficiency virus (HIV), PML was most commonly associated with HIV infection where it occurs in $3-7 \%$ of patients, and is an acquired immunodeficiency syndrome (AIDS) defining illness. [7, 8, 9] Progressive Multifocal Leucoencephalopathy can affect organ transplant recipients, patients with lymphoma, leukaemia, those on long term corticosteroids and other immunosuppressive therapies. Human polyomavirus 2, induced PML has been reported most frequently in association with the use of natalizumab to treat patients with relapsing remitting multiple sclerosis. $[10,11]$ Many other monoclonal antibodies have been implicated in PML in the setting of MS and other autoimmune diseases such as rheumatoid arthritis, psoriatic arthritis (PsA), psoriasis and haematological disease (see Table 1). $[12,13,14]$ The risk of PML occurring in HPyV2 seropositive patients treated with natalizumab ranges from 0.56 to 1.6 per 1000 patients $(95 \% \mathrm{Cl})$ in the first 2 years of treatment. The risk of PML development in patients treated with natalizumab who are seronegative for HPyV2 is estimated at 0.09 per 1000 patients treated $(95 \% \mathrm{Cl} 0-0.48)$. As HPyV2 is sine qua non for PML it is presumed that PML in those who are antibody negative represent a false negative antibody test. [11] There has been recent interest in PML in dermatology because of reports linking PML and fumaric acid ester therapy. [15] There have been 19 cases reported to date, 14 of whom had psoriasis. [16] Apart from one case all patients had a lymphocyte count below $0.7 \times 10^{9} / \mathrm{L}$. The other patient was on Psorinovo ${ }^{\circledR}$ (a compounded form of dimethylfumarate/fumaric acid ester) and developed PML at a lymphocyte count of $0.8 \times 10^{-9}$. [17]

There are no data on HPyV2 antibody prevalence in psoriasis patients. HPyV2 testing may be a useful adjunct in determining the risk of PML in psoriasis patients requiring therapy particularly with dimethylfumarate. 


\section{Objectives}

Our primary aim was to assess the seroprevalence of HPyV2 JCV in psoriasis. The secondary aim was to measure the prevalence of HPyV2 viruria in a psoriasis population. We assessed the treatment and patient specific characteristics in each group.

\section{Study design}

We recruited 248 patients with moderate to severe psoriasis after ethical approval and obtained written informed consent. Patients were recruited from a specialist clinic for psoriasis and comprised of three groups. Cohort 1 included moderate to severe psoriasis patients treated with systemic therapies - (95), predominantly methotrexate (25) and biologic agents -predominantly anti-TNF alpha therapies (47), for psoriasis. Cohort 2 included those treated with fumaric acid esters (84) (Fumaderm ${ }^{\circledR}$ ) and cohort $3(69)$ were psoriasis patients not receiving systemic agents.

Serum was taken for IgG class antibodies against HPyV2. Urine samples for PCR HPyV2 analysis were collected in 89 patients in the systemic/biologics group (cohort $1(n=95))$ of the total group of 248 patients. We recorded lymphocytes counts in all three groups contemporaneously withHPyV2 antibodies.

Baseline demographics of the three cohorts were obtained. At recruitment, baseline PASI (psoriasis area and severity index), DLQI (dermatology life quality index) and current treatment were recorded.

\section{HPyV2 enzyme immunoassay}

The HPyV2 IgG enzyme immunoassay was performed at University of Helsinki as previously described by Kardas et al. 2014, with some modifications. The specificity of the assay is 
$97.78 \%$ and a sensitivity of $95.87 \%$ as determined previously in an inter- and intralaboratory comparison. [18] In brief, streptavidin-coated microwell plates, (UniverSA96Lockwell, Kaivogen Ltd, Finland) were coated with biotinylated HPyV2 virus-like particles (VLPs) (180 ng/well). A streptavidin-coated well served as the streptavidin-background control for each sample and each control. Serum samples were diluted 1:100 and tested in duplicate. Three control sera (negative control, "HPyV2-IgG-Index" control and high positive control) were tested in all assays. After a washing step, horseradish peroxidase conjugated anti-human IgG (Dako, Agilent Technologies) was added for 60 minutes. Substrate

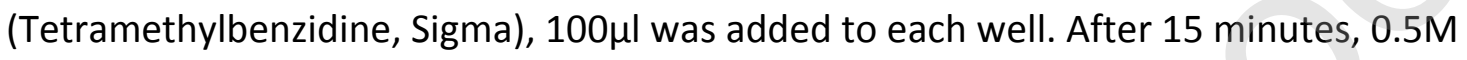
sulphuric acid was added and the absorbances were measured at $450 \mathrm{~nm}$. The reagent blank absorbance and the streptavidin background absorbance were subtracted from the absorbance of the samples and the controls. The results were calculated as an index: the absorbance (OD) of the sample divided by the absorbance of the "HPyV2 IgG Index Control" serum. All positive sera (Index $\geq 0.40)$ and borderline $(0.16<$ Index $<0.40)$ value were retested by pre-adsorption with the non-biotinylated VLPs. Briefly, the sera (1:100) were diluted in buffer containing VLP blocking antigen $(10 \mu \mathrm{g} / \mathrm{ml})$ and incubated at $4^{\circ} \mathrm{C}$ for 90 minutes. The assay was carried out as outlined above. The \% inhibition is calculated as the [(unadsorbed OD - adsorbed OD) / unadsorbed OD] X $100=\%$ inhibition. The result was interpreted as HPyV2 -specific if the inhibition was $>45.0 \%$.

\section{Detection of HPyV2 DNA in urine}

The RealStar ${ }^{\circledR}$ HPyV2 PCR Kit (Altona Diagnostics) is a CE marked IVD approved diagnostic test was used for detection of HPyV2 DNA in urine samples obtained from 89 patients in cohort 1. This assay which targets the large T antigen of HPyV2, includes a heterologous 
amplification system (internal control) to identify possible PCR inhibition and to confirm the integrity of the reagents of the kit. DNA was extracted from $140 \mu$ l of urine with the Biomerieux Easy MAG extraction system (bioMerieux) with an elution volume of $60 \mu$ l. The amplification was performed on the ABI 7500 FAST Analyser using $10 \mu \mathrm{l}$ of eluate and $15 \mu \mathrm{l}$ of the mastermix. The following assay parameters were used: 10 mins at $95^{\circ} \mathrm{C}, 45$ cycles at $15 \mathrm{~s}$ at $95^{\circ} \mathrm{C}$ and $60 \mathrm{~s}$ at $58^{\circ} \mathrm{C}$. The kit contains 4 quantification standards with concentrations ranging from 10 to 10,000 copies/ $\mu$ l. Furthermore, a QC, HPyV2QC-01 (Qnostics Q control, Scotland) which served as a positive control, was run in all assays.

\section{Results}

$52 \%$ of the systemic/ biologic group were seropositive for HPyV2, 36\% were seronegative and $11.5 \%$ had equivocal tests. $50 \%$ of those receiving fumaric acid esters were seropositive for JCV , $44 \%$ seronegative and $5 \%$ equivocal. $48 \%$ of those not receiving systemic treatment were seropositive for HPyV2, 35\% were seronegative and 17\% were equivocal. Urinary PCR $(n=89)$ for HPyV2 was positive in $21 \%$ of patients on systemic therapy (cohort $1(n=95))$. This figure has been replicated in previous studies. In our group, 95\% of those with HPyV2 viruria were also HPyV2 seropositive. HPyV2 viruria is thought to represent active viral replication.

In the systemics and biologic group ( $n=95), 52 \%$ of the group were HPyV2 seropositive. The average age was 49 years (range $21-75$ years) and the majority male (59\%) versus (41\%) female, respectively. The average PASI was 4.4 (range $0-26.2$ ) and $30 \%$ of this cohort had a diagnosis of PsA. Of these, $15 \%$ were smokers.

In the dimethylfumarate (Fumaderm ${ }^{\circledR}$ ) cohort $50 \%$ were HPyV2 seropositive. In this group $22.5 \%$ smoked, the majority were male (63\%) versus (37\%) female. The average age was 
42.7 years (range 17-75 years). The average PASI was 5.5 (range $0-12.2$ ) and the average weight was $88 \mathrm{kgs}$. In contrast to cohort 1 , only $1.6 \%$ had a diagnosis of PsA.

In those patients not receiving systemic treatment (Cohort 3), $48 \%$ were seropositive for HPyV2. The average age was 41 years (range 19-75 years), with an average PASI of 10.5 (range 5.6-17.4). Once again the majority were (65\%) male versus (35\%) female. Psoriatic arthritis occurred in $5.7 \%$ of this group. One third (32\%) of cohort 3 were smokers. The average BMI was 26.6. (See table 2.)

\section{Lymphocyte counts}

In cohort 1 (systemics/biologics) the average lymphocyte count was $1.87 \times 10^{-9}$ (nadir 0.5 , peak 3.5). The average lymphocyte count in cohort 2 (FAEs) was $1.37 \times 10^{-9}$ (nadir 0.4 , peak 2.8) and in cohort 3 -no systemic therapy- the average lymphocyte count was $2.03 \times 10^{-9}$ (nadir 0.6, peak 11.9). HPyV2 seropositivity was present in approximately half of all those lymphopenic patients (table 3). There was no association between HPyV2 seropositivity and lymphopenia. Grades of lymphopenia are outlined in table 4.

\section{Discussion}

Active viral replication of HPyV2 in sera has been described previously in a small prospective study of 30 patients with psoriasis $(n=15)$ and psoriatic arthritis $(n=15)$. That study examined a 6 month period of active viral replication using real time PCR to measure HPyV2 DNA in serum and skin rather than lifetime exposure i.e. antibody positivity.. Active viral replication was reported in up to $60 \%$ of patients. No viral DNA was detected in skin biopsies. [19] 
In our study, we measured IgG HPyV2 seroprevalence in a group of 248 patients with moderate to severe psoriasis. From our data, psoriasis patients showed a similar seroprevalence to that of the normal population. There was no significant difference between those on systemic/biologic agents, fumaric acid esters (Fumaderm ${ }^{\circledR}$ ) or those not on systemic immunosuppression for their psoriasis. The prevalence of viruria represents closely the previous reports of HPyV2 viruria. $[20,21]$ Urinary PCR for HPyV2 was positive in $21 \%$ of those patients on systemic therapy $(n=89) .95 \%$ of these were also HPyV2 seropositive.

Recent reports of PML occurring in patients on fumaric acid esters for psoriasis, led to a directive from the European Medicines Agency outlining more intense monitoring of these patients. [22] They advise monthly monitoring of lymphocyte counts and halving the dose if patients develop grade 1 lymphopenia and stopping treatment if this persists. This contrasts with the guidance issued for multiple sclerosis patients on Tecfidera ${ }^{\circledR}$ or BG-12 dimethylfumarate, whose lymphocytes are monitored on a 3-monthly basis despite the higher annual risk of developing PML of approximately 1 in 1000. [11]

The development of PML in psoriasis patients is dependent on lymphopenia and the presence of HPyV2 infection. Our study showed that approximately $50 \%$ of patients with psoriasis are not at risk of PML as they do not have HPyV2 infection. This study also showed that systemic immunosuppression does not increase the risk of HPyV2 infection and that psoriasis per se does not increase this either.

Our study is limited by small numbers. Current studies are assessing the longitudinal risk of developing HPyV2 infection by re-testing psoriasis patients over several time periods to assess the rate of HPyV2 infection. 


\section{Conclusion}

Psoriasis patients appear to have similar infection rates with HPyV2 compared to the general population. Systemic immunosuppression and/or treatment with fumaric acid esters does not appear to increase the risk of HPyV2 infection in psoriasis patients. The risk of developing PML in HPyV2 negative patients appears to be exceedingly low (false negative rates $2.5-2.7 \%)$. [11] Cessation of FAEs necessitates the need for alternative therapy, commonly biologic therapy, which carries a risk of infection requiring hospitalization in 1 per 100 patient years and a risk of death in 1 per 1000 patient years. This is in contrast to the rare occurrence of PML in the background population of $<0.3 / 100,000$ patient years [6] and 0.09 per 100 patients treated who are seronegative for HPyV2 virus. [11] Under current clinical prescribing guidelines this common clinical scenario presents a risk/benefit dilemma.

We propose that HPyV2 infection status is relevant in those psoriasis patients with lymphocyte counts between $0.5-0.7 \times 10^{-9}$ who are well controlled on dimethylfumarate.

Further larger studies are needed to ascertain whether HPyV2 infection status may be useful for PML risk stratification in psoriasis patients requiring treatment with DMF.

Word count 1972. 
${ }^{a}$ OE Molloy: Conceptualization, Methodology, data curation, Visualization, Writing of original draft and editing.

${ }^{a}$ A Malara: Data curation.

bJ Hassan: Investigation, Writing

${ }^{a}$ M Lynch: Data curation.

aj Clowry: Data curation.

${ }^{\mathrm{d}} \mathrm{K}$ Hedman: Investigation.

${ }^{b}$ CF De Gascun,

Conceptualization, Resources, Investigation, Writing-review and editing.

a,c B Kirby

Conceptualization, Methodology, Writing-Review and editing, Supervision.

Declaration of conflicts of interest.

none

Acknowledgements: We would like to acknowledge Professor Klaus Hedman Professor of Virology, Huslab, University of Helsinki, Finland for the HPyV2 analysis. 
References :

[1]. Zu Rhein GM, Chou SM. "Particles Resembling Papova Viruses in Human Cerebral Demyelinating Disease". Science (New York, N.Y.)1965; 148 (3676).

[2]. Padgett BL, Walker DL et al. (1971). "Cultivation of papova-like virus from human brain with progressive multifocal leucoencephalopathy". Lancet 1971; 1 (7712): 1257-60.

[3]. Egli, A., Infanti, L., Dumoulin, A., Buser, A., Samaridis, J., Stebler, C., \& Hirsch, H. H. (2009). Prevalence of polyomavirus BK and JC infection and replication in 400 healthy blood donors. Journal of Infectious Diseases, 199(6), 837-846.

[4].White MK, Khalili K. Pathogenesis of progressive multifocal leukoencephalopathy revisited. Journal of Infectious Diseases 2011; 203: 578-586.

[5]. Molloy ES, Calabrese LH. Progressive multifocal leukoencephalopathy: a national estimate of frequency in systemic lupus erythematosus and other rheumatic diseases. Arthritis and Rheumatism 2009; 60: 3761-3765.

[6]. Arkema EV, van Vollenhoven RF, Askling J. Incidence of progressive multifocal leukoencephalopathy in patients with rheumatoid arthritis: a national population-based study. Ann Rheum Dis 2012; 71:1865-7.

[7]. BERGER JR, KASZOVITZ B, POST MJD, DICKINSON G. Progressive Multifocal Leukoencephalopathy Associated with Human Immunodeficiency Virus Infection: A Review of the Literature with a Report of Sixteen Cases. Ann Intern Med. 1987; 107:78-87. doi: 10.7326/0003-4819-107-1-78. 
[8]. Berger, J.R. Progressive multifocal leukoencephalopathy in acquired immunodeficiency syndrome: Explaining the high incidence and disproportionate frequency of the illness relative to other immunosuppressive conditions. Journal of NeuroVirology (2003) 9(Suppl 1): 38. https://doi.org/10.1080/13550280390195261.

[9.]Martinez AJ, Sell M, Mitrovics T, et al. The neuropathology and epidemiology of AIDS: a Berlin experience-a review of 200 cases, Pathol Res Pract, 1995, vol. 191 (pg. 427-43) [10]. Van Assche G, Van Ranst M, Sciot R, Dubois B, Vermeire S, Noman M, et al. Progressive multifocal leukoencephalopathy after natalizumab therapy for Crohn's disease. N Engl J Med 2005; 353: 362-3).

[11]. Risk of Natalizumab-Associated Progressive Multifocal Leukoencephalopathy. Bloomgren G, Richman S. NEJM 2012; 366:1870-1880.

[12]. Bohra C, Sokol L, Dalia S. Progressive Multifocal Leukoencephalopathy and Monoclonal Antibodies: A Review. Cancer Control. 2017;24(4):1073274817729901.

doi:10.1177/1073274817729901

[13 Raisch DW, Rafi JA, Chen C, Bennett CL. Detection of cases of progressive multifocal leukoencephalopathy associated with new biologicals and targeted cancer therapies from the FDA's adverse event reporting system. Expert Opin Drug Saf. 2016;15(8):1003-1011. doi:10.1080/14740338.2016.1198775

[14] Yukitake, M. (2018), Drug-induced progressive multifocal leukoencephalopathy in multiple sclerosis: A comprehensive review. Clin Exp Neuroimmunol, 9: 37-47. doi:10.1111/cen3.12440 
[15] Major EO. Progressive multifocal leukoencephalopathy in patients on immunomodulatory therapies. Annual Review of Medicine 2010; 61: 35-47.

[16]. Gieselbach, RJ, Muller-Hansma, A.H., Wijburg, M.T. et al. Progressive multifocal leukoencephalopathy in patients treated with fumaric acid esters: a review of 19 cases. J Neurol (2017) 264: 1155. https://doi.org/10.1007/s00415-017-8509-

[17]. van Oosten BW, Killestein J, Barkhof F, Polman CH, Wattjes MP. PML in a patient treated with dimethyl fumarate from a compounding pharmacy. New England Journal of Medicine. 2013; 368:1658-9.

[18]. Kardas P, Sadeghi M, Weissbach F.H., Chen T, Hedman L, Auvinen E, Hedman K, Hirsch H.H. Inter- and Intralaboratory Comparison of JC Polyomavirus Antibody Testing Using Two Different Virus-Like Particle-Based Assays. Clinical and Vaccine Immunology Oct 2014, 21 (11) 1581-1588; DOI: 10.1128/CVI.00489-14

[19]. Nardis, C., Anzivino, E., Bellizzi, A., Rodio, D. M., De Pità, O., Chiarini, F. and Pietropaolo, V. (2012), Reactivation of human polyomavirus JC in patients affected by psoriasis vulgaris and psoriatic arthritis and treated with biological drugs: Preliminary results. J. Cell. Physiol., 227: 3796-3802. doi:10.1002/jcp.24089).

[20]. Hogan TF et al. Human Polyomavirus infections with JC virus and BK virus in Renal Transplant patients. Annals of Internal Medicine 1980 vol: 92 (3) pp: 373

[21]. Karalic, D., Lazarevic, I., Banko, A. et al. Analysis of variability of urinary excreted JC virus strains in patients infected with HIV and healthy donors. J. Neurovirol. (2018) 24: 305313. [Jhttps://doi.org/10.1007/s13365-017-0608-y. 
[22]. Updated recommendations to minimise the risk of the rare brain infection PML with

Tecfidera.www.ema.europa.eu/.../news_and_events/news/2015/10/news_detail_002423.js p\&mid $=W C 0 b 01 a c 058004 d 5 c 1$ 


\begin{tabular}{|c|c|c|c|}
\hline \multicolumn{4}{|c|}{ PML associated with monoclonal antibodies } \\
\hline $\begin{array}{ll}\text { Underlying } & \text { medical } \\
\text { condition } & \end{array}$ & Drug implicated & Molecular target & Risk of PML \\
\hline Multiple sclerosis & Natalizumab & $\alpha-4$ integrin & 1 in 1000 \\
\hline \multirow[t]{2}{*}{ Rheumatoid arthritis } & Rituximab & CD20 & 1 in 32,000 \\
\hline & Abatacept & CD80, CD86 & \\
\hline Systemic lupus & Belimumab & BAFF, BLys & \\
\hline \multicolumn{4}{|l|}{ Haematological disease } \\
\hline CLL & Alemtuzumab & CD52 & low \\
\hline B cell lymphoma & Ibrutonomab tituxen & CD20 & 2 \\
\hline CLL & Obinutuzumab & CD20 & \\
\hline $\begin{array}{l}\text { Hodgkin's Lymphoma, } \\
\text { ALCL }\end{array}$ & Brentuximab vedotin & CD30 & 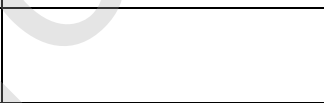 \\
\hline Colon cancer/NSCL cancer & Cetuximab & EGF receptor & \\
\hline Colon cancer & Bevacizumab & VEGF-A & \\
\hline \multirow[t]{2}{*}{ Acute organ rejection } & Muromonab & CD-3 & \\
\hline & Basiliximab & CD-25 & \\
\hline \multirow[t]{2}{*}{ Psoriasis/psoriatic arthritis } & Efalizumab & CD11a & Withdrawn in 2009 \\
\hline & $\begin{array}{l}\text { Infliximab } \\
\text { Etanercept } \\
\text { Adalimumab }\end{array}$ & TNF- $\alpha$ & low \\
\hline
\end{tabular}

Table 1. [12,13,14.] 


\begin{tabular}{|c|c|c|c|}
\hline $\begin{array}{l}\text { Patient } \\
\text { Demographics }\end{array}$ & Cohort $1(n=95)$ & Cohort $2(n=84)$ & Cohort $3(n=69)$ \\
\hline Antibody positivity & $52 \%$ & $50 \%$ & $48 \%$ \\
\hline Average age & $\begin{array}{l}49 \\
\text { (range } 21-75 \text { years) }\end{array}$ & $\begin{array}{l}43 \\
\text { (range 17-75 years) }\end{array}$ & $\begin{array}{l}41 \\
\text { (range 19-75 years) }\end{array}$ \\
\hline Sex & $\begin{array}{l}\text { Male } 59 \% \\
\text { Female } 41 \%\end{array}$ & $\begin{array}{l}\text { Male } 65 \% \\
\text { Female } 35 \%\end{array}$ & $\begin{array}{l}\text { Male } 65 \% \\
\text { Female } 35 \%\end{array}$ \\
\hline $\begin{array}{l}\text { Average PASI } \\
\text { (Psoriasis area and } \\
\text { severity index) }\end{array}$ & $4.4(0-26.2)$ & $5.5(0-12.2)$ & $10.5(5.6-17.4)$ \\
\hline $\begin{array}{l}\text { Average Lymphocyte } \\
\text { count }\end{array}$ & $\begin{array}{l}1.86 \times 10^{-9} \\
\text { (nadir 0.5, peak 3.5) }\end{array}$ & $\begin{array}{l}1.38 \times 10^{-9} \\
\text { (nadir 0.4, peak 2.8) }\end{array}$ & $\begin{array}{l}2.03 \times 10^{-9} \\
\text { (nadir } 0.6, \text { peak } 11.9 \text { ) }\end{array}$ \\
\hline Smoking status & $21.8 \%$ & $22.5 \%$ & $32 \%$ \\
\hline Presence of PsA & $30 \%$ & $1.6 \%$ & $5.7 \%$ \\
\hline PsA: Ps & $3: 7$ & $1: 61$ & $1: 22$ \\
\hline Urinary JCV & $\begin{array}{l}(n=89) \\
u J C V \text { pos in } 21 \%\end{array}$ & $\begin{array}{l}(n=1) \\
\text { uJCV pos in } 1 \%\end{array}$ & \\
\hline
\end{tabular}

Table 2. 


\begin{tabular}{|c|c|c|c|}
\hline $\begin{array}{c}\text { Grades of } \\
\text { lymphopenia }\end{array}$ & $\begin{array}{l}\text { Systemics/biologics } \\
\text { Cohort } 1(n=95)\end{array}$ & $\begin{array}{l}\text { Fumaric acid esters } \\
\text { Cohort } 2(n=84)\end{array}$ & $\begin{array}{l}\text { No treatment } \\
\text { Cohort } 3(n=69)\end{array}$ \\
\hline $\begin{array}{l}\text { 1. An ALC of <Lower } \\
\text { normal limit to } 0.8 \\
x 10-9\end{array}$ & $5.9 \%$ (7) 3-JCVpos & $6 \%$ (4) 2-JCVpos & $0 \%$ \\
\hline 2. 0.5 to $0.8 \times 10-9$ & $8.5 \%$ (10) $5 \mathrm{JCV}$ pos & 15\% (10) 5-JCVpos & $1.4 \%(1)$ \\
\hline 3. $0.2-0.5 \times 10-9$ & nil & $1.5 \%(1)$ & nil \\
\hline 4. $<0.2 \times 10-9$ & nil & nil & nil \\
\hline 5.0 & nil & nil & nil \\
\hline
\end{tabular}

Table 3. 


\begin{tabular}{|c|c|c|c|}
\hline $\begin{array}{c}\text { Grades of } \\
\text { lymphopenia }\end{array}$ & $\begin{array}{l}\text { Systemics/biologics } \\
\text { Cohort } 1 \text { ( } n=95)\end{array}$ & $\begin{array}{l}\text { Fumaric acid esters } \\
\text { Cohort } 2(n=84)\end{array}$ & $\begin{array}{l}\text { No treatment } \\
\text { Cohort } 3(n=69)\end{array}$ \\
\hline $\begin{array}{l}\text { 1. An ALC of < Lower } \\
\text { normal limit to } 0.8 \\
\times 10-9\end{array}$ & $5.9 \%$ (7) 3-JCVpos & $6 \%(4)$ 2-JCVpos & $0 \%$ \\
\hline 2. 0.5 to $0.8 \times 10-9$ & 8.5\% (10) $5 \mathrm{JCV}$ pos & 15\% (10) 5-JCVpos & $1.4 \%(1)$ \\
\hline 3. $0.2-0.5 \times 10-9$ & nil & $1.5 \%(1)$ & nil \\
\hline 4. $<0.2 \times 10-9$ & nil & nil & nil \\
\hline 5.0 & nil & nil & nil \\
\hline
\end{tabular}

Table 3. 